12. Kacmarek RM, Dimas S, Mack CW. The essentials of respiratory care, 4th edition. St. Louis:Mosby|Elsevier; 2005:103.

13. L'Her E, Roy A. Bench tests of simple, handy ventilators for pandemics: performance, autonomy, and ergonomy. Respir Care 2011;56(6):751-760.

14. Lyazidi A, Thille AW, Carteaux G, Galia F, Brochard L, Richard JC. Bench test evaluation of volume delivered by modern ICU ventilators during volume-controlled ventilation. Intensive Care Med 2010;36(12):2074-2080.

15. Wallon G, Bonnet A, Guérin C. Delivery of tidal volume from four anaesthesia ventilators during volume-controlled ventilation: a bench study. Br J Anaesth 2013; 110(6):1045-1051.

16. Lofaso F, Fodil R, Lorino H, Leroux K, Quintel A, Leroy A, Harf A. Inaccuracy of tidal volume delivered by home mechanical ventilators. Eur Respir J 2000;15(2):338341.

17. Duchateau P, Guérin C. Tidal volume delivery from ICU ventilators at BTPS conditions: a bench study. Respir Care 2013; 58(4):623-632.

\section{Near-Infrared Spectroscopy with Vascular Occlusion Test May Not Be the Adequate Tool to Explore Microcirculation in Pulmonary Arterial Hypertension}

\section{To the Editor:}

Dimopoulos et $\mathrm{al}^{1}$ likened the microcirculation of stable patients with pulmonary arterial hypertension (PAH) and congestive heart failure (CHF) and matched normal subjects. They found an effect on the microcirculation, measured by near-infrared spectroscopy with vascular occlusion test (NIRSVOT), in patients with $\mathrm{PAH}$ and $\mathrm{CHF}$ and a deleterious action of hyperoxia (performed in the PAH group). Despite a very meticulous work and a conclusion that seems fair and pragmatic, their results should be interpreted carefully. I would like to raise several issues.

First, the authors did not comment on the role of hypoxemia in patients with $\mathrm{PAH}$ in their study. A partial means of moderating this would have been to assess the extraction of tissue oxygen $\left(\mathrm{O}_{2}\right)$ as a surrogate of microcirculatory function. ${ }^{2}$ Elevation of the extraction before VOT would indicate microcirculatory dysfunction with decreased $\mathrm{O}_{2}$ supply to tissue in local demand-supply dependence. This value can be obtained noninvasively and calculated as follows: microvascular oxygen extraction rate $(\mu \mathrm{OER})=\left(\mathrm{S}_{\mathrm{pO}_{2}}-\mathrm{S}_{\mathrm{tO}_{2}}\right) / 0.5 \times \mathrm{S}_{\mathrm{pO}_{2}}($ where $\mathrm{S}_{\mathrm{tO}_{2}}$ is muscle tissue oxygenation). When fit for $\mathrm{S}_{\mathrm{pO}_{2}}, \mu \mathrm{OER}$ values were 33.6, 31, 28, and 20.3 for $\mathrm{PAH}$ in the basal state and hyperoxia, $\mathrm{CHF}$, and normal subjects, respectively. A discussion of these results (yet more abnormally high values in $\mathrm{PAH}$ ) and the role of chronic tissue hypoxia would have been interesting. Accordingly, a decrease in $\mathrm{O}_{2}$ consumption is seen in tissue with chronic hypoxia, termed conformance. ${ }^{3}$ Are we confronted with a paradoxical response to hypoxia (greed for $\mathrm{O}_{2}$, opposite what is expected with conformance) or microvascular dysfunction? Nevertheless, the paucity of data on cardiac output and the role of chronic hypoxia make this derived value questionable. One can also imagine a different behavior of cells in chronic hypoxia, further amending the dynamic curves (ie, $\mathrm{O}_{2}$ consumption rate, reactive hyperhemia time, and time interval) compared with the princeps work during sepsis. ${ }^{4}$

Accordingly, elevated venous pressure has been related to impaired microvascular tissue perfusion. ${ }^{5}$ Thus, a possible modification of post-capillary venous vessel capacitance would obscure NIRS-VOTderived values. In PAH patients, the role of such a right-sided outflow obstruction has been overlooked in this study. Moreover, from several intrinsic technological limiting factors, NIRS-VOT explores a derivative of the values of tissue oxygenation and may be dependent on the diffusion of $\mathrm{O}_{2}$ in the context of hyperoxia.

I think that it may be reasonable to conclude that those patients with PAH likely had a microcirculatory dysfunction, potentially exacerbated by hyperoxia. However, a validation of NIRS-VOT to explore the microcirculation is required in this context of chronic hypoxemia and right-sided overpressure before more formal conclusions can be made. A joint (or with replacement of NIRS) assessment by sidestream dark field imaging would be interesting.

Sébastien Champion MD

Réanimation Médicale et Toxicologique Lariboisière Hospital Paris, France

The author has disclosed no conflicts of interest.

DOI: $10.4187 /$ respcare.02996

\section{REFERENCES}

1. Dimopoulos S, Tzanis G, Manetos C, Tasoulis A, Mpouchla A, Tseliou E, et al. Peripheral muscle microcirculatory alterations in patients with pulmonary arterial hypertension: a pilot study. Respir Care 2013;58(12):2134-2141.

2. Hogan CJ, Ward KR, Kontos MC, Thacker LR, Pittman R. Peripheral tissue oxygenation improves during $\mathrm{ED}$ treatment of acute heart failure. Am J Emerg Med 2012;30(1): 196-202.

3. Schumacker PT, Chandel N, Agusti AG. Oxygen conformance of cellular respiration in hepatocytes. Am J Physiol 1993; 265(4 Pt 1):L395-L402.

4. Creteur J, Carollo T, Soldati G, Buchele G, De Backer D, Vincent JL. The prognostic value of muscle $\mathrm{S}_{\mathrm{tO}_{2}}$ in septic patients. Intensive Care Med 2007;33(9):1549-1556.

5. Vellinga NA, Ince C, Boerma EC. Elevated central venous pressure is associated with impairment of microcirculatory blood flow in sepsis: a hypothesis generating post hoc analysis. BMC Anesthesiol 2013;13(1):17.

Near-Infrared Spectroscopy With Vascular Occlusion Test May Not Be the Adequate Tool to Explore Microcirculation in Pulmonary Arterial Hypertension-Reply

\section{In Reply:}

We thank Dr Champion for his particular interest in our study and his thorough comments. However, we would like to share our concerns related to his comments.

In our point of view, we should use the microvascular oxygen extraction rate with caution, as it is not yet a valid accurate index to use. This index does not take into account all of the factors that influence oxygen delivery, such as cardiac output, serum hemoglobin levels, and hemoglobin dissociation curve, and to the best of our knowledge, it has not been investigated previously in patients with chronic hypoxemia.

Resting tissue oxygen saturation $\left(\mathrm{S}_{\mathrm{tO}_{2}}\right)$ values depend mainly on the ratio of tissue oxygen delivery to tissue oxygen extraction. In our study, ${ }^{1}$ pulmonary arterial hypertension $(\mathrm{PAH})$ patients presented with a relatively normal cardiac index (median value of $2.5 \mathrm{~L} / \mathrm{min} / \mathrm{m}^{2}$ ) and normal serum hemoglobin levels (median value of $16 \mathrm{~g} / \mathrm{dL}$ ) with mild hypoxemia $\left(\mathrm{S}_{\mathrm{pO}_{2}}\right.$ median value of 94\%), the latter being a possible factor that might slightly decrease tissue oxygen supply. However, tissue oxygen delivery de- 
pends also on regional tissue perfusion, which seems to be altered in these patients.

Supporting evidence provided using the near-infrared spectroscopy (NIRS) 3-min vascular occlusion technique in our study showed that there was a reduction in oxygen consumption rate in $\mathrm{PAH}$ patients compared with healthy subjects (median values of $33 \%$ and $44 \% / \mathrm{min}$, respectively), making the mechanism of increased oxygen extraction an unlikely explanation of the decrease in resting $\mathrm{S}_{\mathrm{tO}_{2}}$ in these $\mathrm{PAH}$ patients. For these reasons, we strongly believe that the main mechanism explaining the decrease in resting $\mathrm{S}_{\mathrm{tO}_{2}}$ is rather a regional impaired tissue perfusion. The presence of an imbalance of autonomic nervous system activity ${ }^{2}$ and the pronounced increased sympathetic overactivity $^{3}$ of local and systemic neurohumoral factors, such as the increased endothelin-1/nitric oxide activity ratio ${ }^{4}$ and the anatomical and functional skeletal muscle alterations (muscle atrophy and mitochondrial dysfunction), 5 in PAH patients are possibly the main mediators of a skeletal muscle mismatch of regional tissue perfusion and oxidative metabolism. These local and systemic alterations may explain the peripheral microcirculatory abnormalities observed using NIRS methodology in PAH patients. Interestingly, an impaired oxygen extraction ratio has been demonstrated previously in $\mathrm{PAH}$ patients during maximal exercise $^{6}$ further supporting the aboveproposed explanatory mechanism.

Thus, the decreased resting $\mathrm{S}_{\mathrm{tO}_{2}}$ reflects mainly the peripheral microcirculatory alterations in PAH rather than an increased oxygen extraction. However, the innovative findings of our study are demonstrated not only by resting $\mathrm{S}_{\mathrm{tO}_{2}}$ values but also by the increased hyperemia time after 3 min of vascular occlusion, indicating important endothelial dysfunction. Moreover, the deleterious hyperoxic breathing effects on endothelial function in $\mathrm{PAH}$ patients that emerged in our study are of particular importance and merit further investigation. These data might have important clinical implications in the use of oxygen therapy in these patients. The mechanisms underlying hyperoxia-induced vasoconstriction effects are nicely described in a recent review from Sjöberg and Singer. ${ }^{7}$

The possible role of right-sided "outflow obstruction" that might affect peripheral microcirculation and NIRS results in PAH patients is of interest. However, more data are needed to clarify better its possible effects in PAH microcirculation prior to any definite conclusion.

We strongly believe that the novel findings of this pilot study will stimulate further investigation that will provide evidence to confirm the present data and more accurate explanatory mechanisms. NIRS with the vascular occlusion technique is a simple valid method that can easily estimate microcirculatory and tissue oxygenation changes useful to daily clinical practice. Its combination with novel, more sophisticated imaging techniques, such as sidestream dark field imaging, may also be helpful to confirm and possibly extend the results of our pilot study.

Stavros Dimopoulos MD Serafim Nanas MD Cardiopulmonary Exercise Testing and Rehabilitation Laboratory

First Critical Care Medicine Department
National and Kapodistrian University of Athens

Athens, Greece on behalf of the authors

The authors have disclosed no conflicts of interest.

DOI: $10.4187 /$ respcare. 03207

\section{REFERENCES}

1. Dimopoulos S, Tzanis G, Manetos C, Tasoulis A, Mpouchla A, Tseliou E, et al. Peripheral muscle microcirculatory alterations in patients with pulmonary arterial hypertension: a pilot study. Respir Care 2013;58(12):2134-2141.

2. Dimopoulos S, Anastasiou-Nana M, Katsaros F, Papazachou O, Tzanis G, Gerovasili $\mathrm{V}$, et al. Impairment of autonomic nervous system activity in patients with pulmonary arterial hypertension: a case control study. J Card Fail 2009;15(10):882-889.

3. Velez-Roa S, Ciarka A, Najem B, Vachiery JL, Naeije R, van de Borne P. Increased sympathetic nerve activity in pulmonary artery hypertension. Circulation 2004; 110(10):1308-1312.

4. Galié N, Manes A, Branzi A. The endothelin system in pulmonary arterial hypertension. Cardiovasc Res 2004;61(2):227-237.

5. Batt J, Ahmed SS, Correa J, Bain A, Granton J. Skeletal muscle dysfunction in idiopathic pulmonary arterial hypertension. Am J Respir Cell Mol Biol 2013;50(10):74-86.

6. Tolle J, Waxman A, Systrom D. Impaired systemic oxygen extraction at maximum exercise in pulmonary hypertension. Med Sci Sports Exerc 2008;40(1):3-8.

7. Sjöberg F, Singer M. The medical use of oxygen: a time for critical reappraisal. J Intern Med 2013;274(6):505-528. 